Gut, 1985, 26, 352-358

\title{
Measurement of gastric emptying in dyspeptic patients: effect of a new gastrokinetic agent (cisapride)
}

\author{
R JIAN, F DUCROT, C PIEDELOUP, J Y MARY, \\ Y NAJEAN, AND J J BERNIER
}

From the Unité de Recherches sur la Physiopathologie de la Digestion et Clinique Gastroentérologique, Hôpital Sait Lazare, Paris, INSERM U 263 Laboratoire de Biostatistiques Université, Paris, and Service de Médecine Nucléaire, Hôpital Saint-Louis, Paris, France

SUMMARY Symptoms suggesting gastroparesis in patients without gastric outlet obstruction are very common but their relation to an objective delay of gastric emptying has been poorly investigated. A dual isotopic technique was used to evaluate patients with non-obstructive dyspepsia (idiopathic and secondary) (part 1) and to assess the effects of a new gastrokinetic agent: cisapride, on gastric emptying in such patients (part 2). Sixty patients with postprandial dyspeptic symptoms (vomiting, nausea, gastric bloating or full feeling) and without lesions at upper endoscopy were studied. They were distributed into three groups: idiopathic dyspepsia $(n=31)$, postvagotomy dyspepsia $(n=16)$ and dyspepsia secondary to medical disorders $(n=13)$. All patients ingested the same ordinary meal; ${ }^{99 \mathrm{~m}}$ Tc sulphur colloid tagged egg white was the solid phase marker and ${ }^{111}$ In chloride was the liquid phase marker. In part 1 , evaluation of gastric emptying in the first 50 patients shows a delay of gastric emptying rate of solids and liquids as compared with controls. Striking differences separate the three groups of patients, however, percentages of delayed gastric emptying rate of solids and or liquids averaged $90 \%$ in postvagotomy or secondary dyspepsia groups whereas it was $44 \%$ in idiopathic dyspepsia group. Moreover, liquid emptying rate was often the only one impaired in idiopathic dyspepsia, and in 12 of the 27 patients of this group the faster emptying rate of liquids as compared with that of solids (always found in normal subjects), could not be evidenced. In part 2, 10 patients entered a double blind cross over study of cisapride ( $8 \mathrm{mg}$ intravenously). A significant increase of solid $(\mathrm{p}<0.01)$ and liquid $(\mathrm{p}<0.05)$ emptying rates was found in patients with initial gastric emptying delay. This study emphasises the importance of an objective evaluation of gastric emptying in the presence of symptoms of gastric stasis and suggests that specific local acting therapy may be useful in patients with identified abnormal gastric emptying.

A gastric emptying delay without any gastric outlet obstruction has recently been shown in several diseases including diabetes, ${ }^{1-3}$ postgastric surgical states,${ }^{45}$ gastric ulcer and chronic gastritis, ${ }^{67}$ reflux oesophagitis, ${ }^{8}$ and systemic neuromuscular disorders. ${ }^{9}$ In most of these diseases, gastric stasis is insidious and devoid of specific symptoms. ${ }^{56810}$ On the other hand, chronic dyspeptic symptoms suggesting gastroparesis often occur without any

Address for correspondence: Dr R Jian. Hôpital Saint-Lazare, 107 rue du Faubourg-Saint-Denis, Paris $\mathrm{X}^{\mathrm{e}}$, France.

Received for publication 15 June 1984 organic disorder (idiopathic dyspepsia); surprisingly, their relationship with a specific functional disorder of the upper gastrointestinal tract and particularly with an objective gastric emptying delay remains poorly investigated.

If chronic dyspeptic symptoms are associated with an objective stasis, a drug enhancing specifically gastric motility could give these patients an opportunity for better therapeutic management. Metoclopramide and domperidone relieve dyspeptic symptoms and enhance gastric motility, ${ }^{11-15}$ however, these drugs also act on brainstem centres by their antidopaminergic 
properties and this could account, at least partially, for their beneficial effects on symptoms. Dissociation between symptom improvement and absence of gastric emptying enhancement found in several works ${ }^{316}$ stresses this last point. Cisapride, is a new gastrokinetic drug devoid of antidopaminergic effect and seems to act directly at gastric level by facilitating acetylcholine release at the myenteric plexus site without cholinomimetic secretory or side effect ${ }^{17}$, however, the effect of this drug on gastric emptying of food has not been evaluated in man.

In this study, we measured gastric emptying rate of the solid and liquid phases of a meal, by a dual isotopic technique, in patients with chronic dyspepsia (idiopathic and secondary to nonobstructive disorders), (a) to evaluate the frequency of an objective gastric emptying delay in such patients, and (b) to test the acute effect of cisapride on gastric emptying in a double blind cross over study.

\section{Methods}

SUBJECTS

Patients with dyspeptic symptoms and without lesions at endoscopy were referred for evaluation of gastric emptying. At least one of the following criteria was required for inclusion in this study: inability to finish a meal, full feeling after a meal, postprandial bloating, nausea, and vomiting; symptoms had to occur after small or normal meals, disappear when fasting, be present for at least three months; at the time of the study no patient was receiving drugs known to influence gastric emptying. Sixty such patients were selected: 40 men, 20 women; $16-73$ years old $(44 \pm 15, S D)$; mean body weight: $58 \pm 10 \mathrm{~kg}$. Symptoms occurred without any organic disease in 31 (idiopathic dyspepsia), after vagotomy in 16 (postvagotomy dyspepsia) 11 truncal vagotomy and five proximal gastric vagotomy; they were associated with miscellaneous disorders including diabetes scleroderma and amyloidosis in 13 (secondary dyspepsia). The three groups were comparable for sex ratio, age, and weight. None of these patients (apart from two in the secondary dyspepsia group) had weight loss or important nutritional deficiencies.

Ten healthy volunteers without digestive symptoms were studied as a control group: eight men and two women; 20 to 63 years old $(39 \pm 10$, mean $\pm S D$ ); mean weight: $67 \pm 12 \mathrm{~kg}$.

All subjects gave informed consent to participate to this study, which was approved by the local human research committee.
TEST MEAL AND MARKERS

All fasted subjects ingested the same meal, prepared with $70 \mathrm{~g}$ coarsely ground steak, $40 \mathrm{~g}$ bread, $10 \mathrm{~g}$ butter, $10 \mathrm{~g}$ sugar, one egg white $(30$ g), $200 \mathrm{ml}$ skimmed milk and $150 \mathrm{ml}$ of water (440 cal; $38 \%$ carbohydrate, $36 \%$ fat, $26 \%$ protein). ${ }^{99 \mathrm{~m}}$ Technetium sulphur colloid $\left({ }^{99 \mathrm{~m}} \mathrm{Tc}: 800 \mu \mathrm{Ci}\right.$ ) mixed with the egg white before cooking was the solid phase marker and ${ }^{111}$ Indium chloride $\left({ }^{111}\right.$ In: $150 \mu \mathrm{Ci}$ ) added to the water was the liquid phase marker. The stability and the specificity of these labellings were previously checked. ${ }^{18}$

\section{PROTOCOLS}

In part 1 of this study the frequency of gastric emptying delay was evaluated in the 50 first patients selected (Table 1) by comparison with the control group. The labelled meal was eaten sitting in front of the gamma camera positioned over the stomach. Immediately after ingestion of the meal, both markers $\left({ }^{99 \mathrm{~m}} \mathrm{Tc},{ }^{111} \mathrm{In}\right)$ were detected simultaneously for two minute periods at 5 minute intervals for 90 minutes. In the 10 last patients selected (part 2), the effect of cisapride on gastric emptying was evaluated (Table 1). Each patient was studied twice (seven to 15 day intervals) in a double blind study with cisapride $(8 \mathrm{mg})$ or a placebo given in randomised order intravenously five minutes before eating. Immediately after the meal, patients were placed in front of the gamma camera for simultaneous detection of both markers; anterior and posterior images, of one minute periods were taken at 20 minute intervals for three hours. Geometric means of anterior and posterior counts were calculated for each image. Radiation dosimetry of these examinations have been previously estimated. ${ }^{18}$

\section{ANALYSIS OF DATA}

Data were stored on discs and processed by a digital computer (Informatek, France): an area of interest corresponding to the stomach was outlined, and radioactivity was counted in this area on each image. All counts were corrected for, scatter of ${ }^{111}$ In activity into the ${ }^{99 \mathrm{~m}} \mathrm{Tc}$ window using phantom sources, and for physical decay of the

Table 1 Number of patients included in the two parts of the study

\begin{tabular}{lll}
\hline & Part 1 & Part 2 \\
\hline Idiopathic dyspepsia & 27 & 4 \\
Postvagotomy dyspepsia & 11 & 5 \\
Secondary dyspepsia & 12 & 1 \\
Total & 50 & 10 \\
\hline
\end{tabular}


markers. All counts were expressed as a fraction of ingested activity (gastric activity measured just after the ingestion of the meal); slopes of individual emptying curves were determined (1) for the solid marker by linear regression analysis and expressed by the emptying rate $\left(\mathrm{a}, \% \mathrm{~min}^{-1}\right)$ and (2) for the liquid marker by exponential regression analysis and expressed by half emptying time $\left(\mathrm{t} \frac{1}{2}, \mathrm{~min}\right)$. In part 1 comparisons between groups were performed by the Mann Whitney test; the evaluation of frequency of gastric stasis was based on the $95 \%$ confidence interval of the 10 control subjects. In part 2 comparisons between cisapride and placebo were performed by analysis of variance.

\section{Results}

PART 1: GASTRIC EMPTYING IN DYSPEPSIA

A significant delay of both liquid and solid gastric emptying was found in the 50 dyspeptic patients: $t \frac{1}{2}$ of the liquid marker was $155 \pm 14$ min, mean \pm SEM (control group: $79 \pm 6 \mathrm{~min} ; \mathrm{p}<0.001$ ) and the solid marker emptying rate was $0.35 \pm 0.03 \% \mathrm{~min}^{-1}$ (controls $0.47 \pm 0.03 \% \mathrm{~min}^{-1} ; \mathrm{p}<0.01$ ). There were striking differences, however, between the three groups of patients: as far as the liquid marker is concerned (Fig. 1) a significant delay of gastric emptying was evidenced in all three groups, but it was less pronounced in the idiopathic dyspepsia group than in the postvagotomy dyspepsia and the secondary dyspepsia groups where dyspepsia can be related to an identified pathology: $t \frac{1}{2}=127 \pm 15 \mathrm{~min}$ (idiopathic dyspepsia) and $187 \pm 22 \mathrm{~min}$ (postvagotomy dyspepsia + secondary dyspepsia) $(p=0.01)$; for the solid marker (Fig. 2) no significant delay was found between the idiopathic dyspepsia group and the control group $\left(0.43 \pm 0.04 \% \mathrm{~min}^{-1}\right.$ and $0.47 \pm 0.03 \% \mathrm{~min}^{-1}$ respectively) whereas a significant stasis was evidenced in the postvagotomy dyspepsia group $(0.20 \pm 0.06, p<0.01)$ and the secondary dyspepsia group $(0.27 \pm 0.06, \mathrm{p}<0.02)$.

Percentages of patients with an objective delay of gastric emptying (emptying rate $\leqslant m-2$ SD from controls) are given in Table 2 . The idiopathic dyspepsia group again differed from the secondary dyspepsia and postvagotomy groups: less than $50 \%$ of idiopathic dyspepsia patients had an objective delay of gastric emptying whereas this was the case in more than $80 \%$ of postvagotomy dyspepsia and secondary dyspepsia patients $(\mathrm{p}<0.02)$.

The mean difference between solid and liquid gastric retention (solid-liquid discrimination) at 90 minutes was $6 \pm 3 \%$ in the idiopathic group versus $16 \pm 7 \%$ in controls $(\mathrm{p}<0.01)$; no significant difference was found for that parameter between

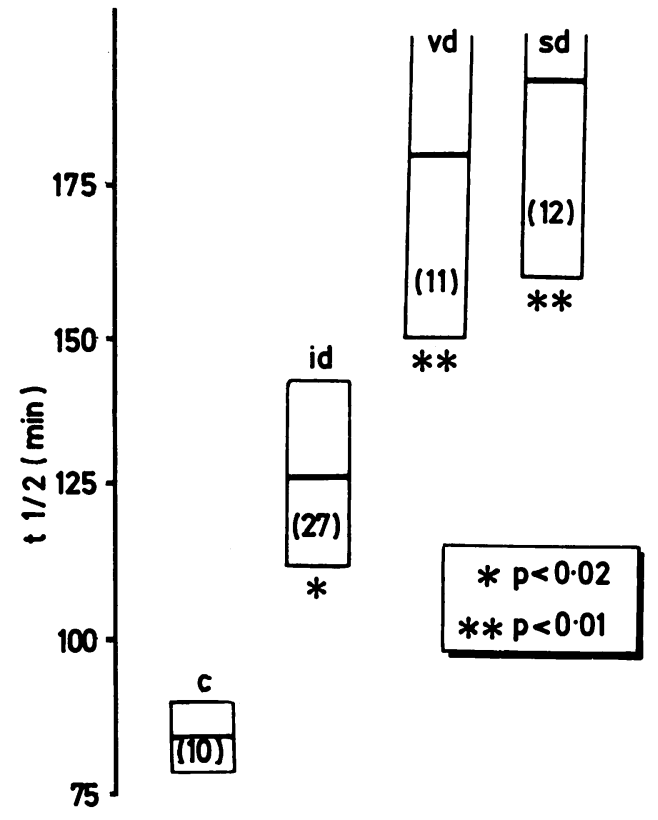

Fig. 1 Gastric emptying of liquids expressed by half emptying time (exponential regression); means $\pm S E M,(n)$ $=$ number of subjects studied. $c=$ controls, $i d=$ idiopathic dyspepsia, $v d=$ postvagotomy dyspepsia, sd = secondary dyspepsia. Statistical comparisons with controls performed with the Mann Whitney test.

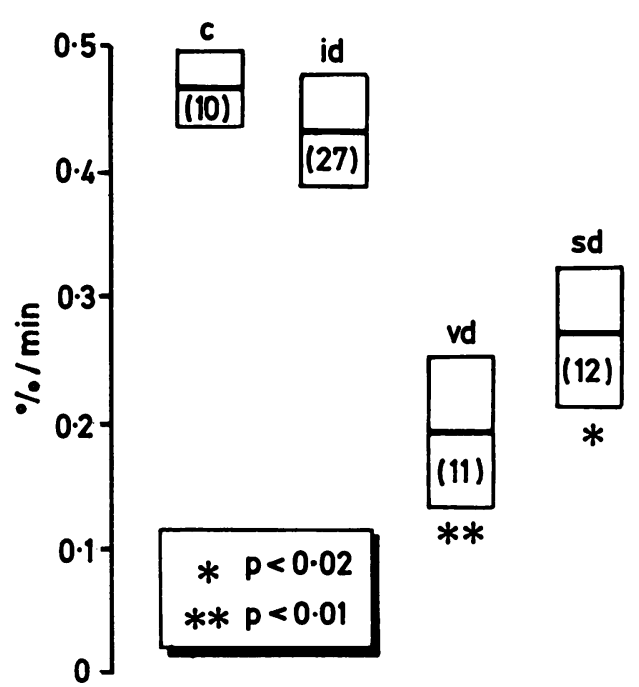

Fig. 2 Gastric emptying of solids expressed by emptying rate (linear regression); means $\pm S E M,(n)=$ number of subjects studied. $c=$ controls, id = idiopathic dyspepsia, $v d$ = postvagotomy dyspepsia, sd = secondary dyspepsia. Statistical comparisons with controls performed with the Mann Whitney test. 
Table 2 Percentages of patients in whom gastric stasis of liquids $(L)$ and solids $(S)$ was evidenced

\begin{tabular}{|c|c|c|c|}
\hline Gastric stasis on * & $L$ & $S$ & $L$ and/or $S$ \\
\hline Idiopathic dyspepsia (27) & $41 \%$ & $26 \%$ & $44 \%$ \\
\hline Postvagotomy dyspepsia (11) & $73 \%$ & $70 \%+$ & $90 \%+$ \\
\hline Secondary dyspepsia (12) & $83 \%$ & $64 \%+$ & $83 \%$ \\
\hline
\end{tabular}

* Stasis of liquids: $t \frac{1}{2} \geqslant m+2$ SD of controls; stasis of solids: $a \leqslant m-2$ SD of controls.

† Data not available for one patient.

controls and postvagotomy dyspepsia or secondary dyspepsia patients. Moreover this discrimination between gastric emptying of solids and liquids always found in the control subjects, cannot be objectivated in 12 of the 27 idiopathic dyspepsia patients (seven with normal and five with delayed gastric emptying rate of solids or liquids).

PART 2: DOUBLE BLIND CONTROLLED TRIAL OF CISPARIDE VERSUS PLACEBO

The effect of cisapride on individual gastric emptying rates of solids and liquids are shown in Figure 3; cisparide enhanced gastric emptying of solids in six of the 10 patients tested and that of liquids in seven; the patients with a preexistent gastric emptying stasis of solids and/or liquids (evidenced by the placebo sequence) were those mainly concerned with this action by cisapride. A
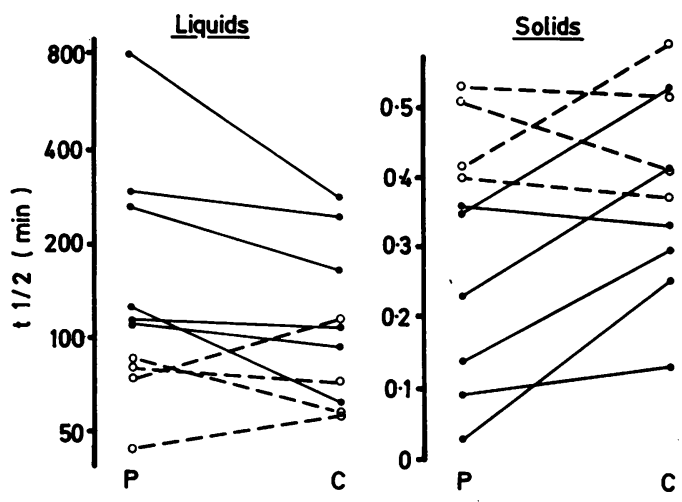

Fig. 3 Effect of cisapride $(C)$ versus placebo $(P)$ on gastric emptying (GE) of liquids (left) and solids (right): individual results. The enhancement of $G E$ by cisapride is evidenced by a decrease of the half GE time (exponential regression) for liquids, and an increase of $G E$ rate (linear regression) for solids. Dotted lines = patients with normal $G E$ on $P$. Solid lines = patients with delayed $G E$ on $P$. significant $(\mathrm{p}<0.05)$ enhancement of gastric emptying of solids by cisapride, but not of liquids $(p=0.06)$ was shown in the whole group of patients; whereas a significant increase of gastric emptying rate of both solids $(\mathrm{p}<0.01)$ and liquids $(p<0.05)$ was evidenced in the subgroup of dyspeptic patients with preexistent delay of gastric emptying (Fig. 4). Although the number of patients in subgroups (idiopathic dyspepsia, postvagotomy dyspepsia, secondary dyspepsia) was too small to perform statistical comparisons, the gastrokinetic action of the cisapride seems to concern both postvagotomy and idiopathic patients (Table 3).

\section{Discussion}

Radioisotopic methods are the most acceptable and accurate means of evaluating gastric emptying in a clinical diagnostic setting. Such a method was used in this prospective study of patients with chronic symptoms of dyspepsia and without gastric outlet obstruction or any other lesion at endoscopy. A double (anterior + posterior)
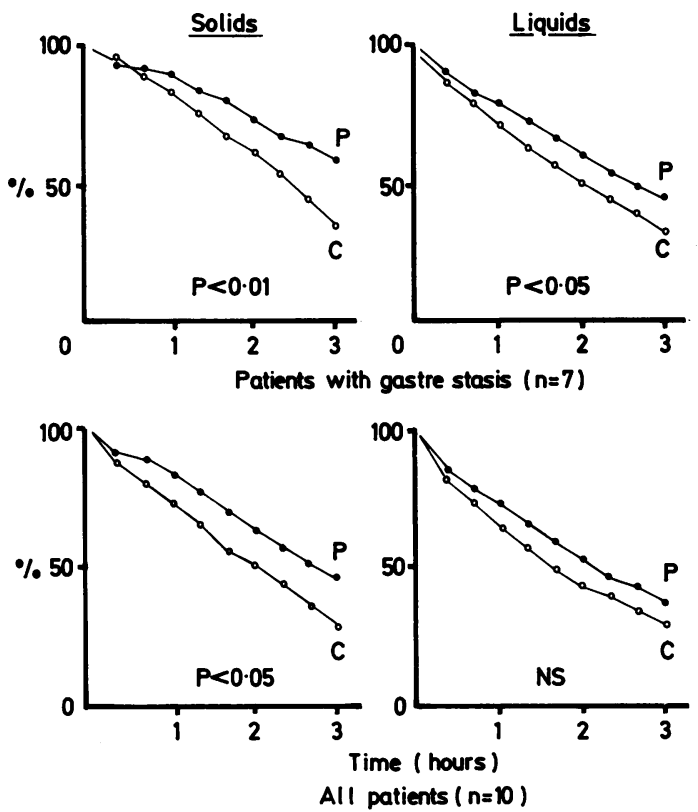

Fig. 4 Effect of cisapride $(C)$ versus placebo $(P)$ on $G E$ of liquids and solids in the whole group of patients tested and the subgroup of patients with gastric emptying delay. Each curve represents \% of ingested marker within stomach versus time (hour). Comparisons were performed by analysis of variance. (NS = non-significant). 
Table 3 Effect of cisapride $(C)$ versus placebo $(P)$ on gastric emptying rates of solids and liquids $(M \pm S E M)$ in 10 dyspeptic patients

\begin{tabular}{|c|c|c|c|c|}
\hline \multirow{4}{*}{$\begin{array}{l}\text { Whole group (10) } \\
\text { Idiopathic } \\
\text { dyspepsia (4) }\end{array}$} & \multicolumn{2}{|c|}{ Solids $\left(\% \mathrm{~min}^{-1}\right)^{*}$} & \multicolumn{2}{|c|}{ Liquids $\left(t_{2}^{\frac{1}{2}}, \min \right)^{*}$} \\
\hline & $P$ & $C$ & $P$ & C \\
\hline & $0 \cdot 31 \pm 0 \cdot 06$ & $0 \cdot 38 \pm 0 \cdot 04$ & $200 \pm 72$ & $126 \pm 25$ \\
\hline & $0.33 \pm 0.06$ & $0.45 \pm 0.06$ & $132 \pm 45$ & $112 \pm 19$ \\
\hline $\begin{array}{l}\text { Postvagotomy } \\
\text { dyspepsia (5) }\end{array}$ & $0 \cdot 25 \pm 0.09$ & $0.33 \pm 0.07$ & $285 \pm 136$ & $151 \pm 47$ \\
\hline
\end{tabular}

* The enhancement of gastric emptying is evidenced by the increase of gastric emptying rate for solids (linear regression) and the decrease of half gastric emptying time for liquids (exponential regression)

detection, as used in part 2 , is probably a more accurate way to measure gastric emptying than the single detection; this procedure was, however, used in part 1 designed to investigate on a routine basis dyspeptic patients; if it probably biases absolute values of gastric emptying, it is very unlikely that it impairs results of this study based on comparisons between groups of patients and control subjects for whom procedures were identical.

When the whole group of patients (idiopathic dyspepsia, postvagotomy dyspepsia and secondary dyspepsia) was considered, a significant delay of gastric emptying was shown for both solids and liquids, thus confirming that symptoms of dyspepsia suggesting gastroparesia do correspond to an objective delay of gastric emptying. Other studies on dyspepsia whatever the aetiology are rare, concern few patients and include subjects with obstructive lesions; they have however given similar results. ${ }^{19-21}$ The substratum of the gastric stasis found in dyspeptic patients remains to be established. A reduction of antral motor activity 131422 and anomalies of the basal electrical rhythm, ${ }^{23}$ however, have been found in such patients; an acido peptic gastric secretion defect that could induce a gastric stasis of solids ${ }^{6}$ has not been investigated in our patients, but seems improbable as their gastroparesis affects both liquids and solids. Finally, central nervous disorders could be at the origin of the stasis as it has been shown that central nervous stimulations induce motor disturbances of the stomach. ${ }^{24}$

In the present study data of dyspeptic patients were also analysed separately according to the aetiology of their dyspeptic symptoms: secondary to medical diseases such as diabetes or neuromuscular disorders, to surgical vagotomy and idiopathic. In the former groups (secondary dyspepsia and postvagotomy dyspepsia) a significant delay of both solid and liquid emptying rates was shown and more than $80 \%$ of these patients have an abnormally delayed gastric emptying rate (Table 2) of solids and/or liquids. This confirms the results of previous studies of diabetic dyspepsia, ${ }^{1-3.1314}$ and of postvagotomy dyspepsia. ${ }^{25} 26$ It is a matter of interest that similar studies performed after vagotomy but in patients without dyspeptic symptoms, evidenced no or only very moderate abnormalities of gastric emptying. ${ }^{4}$ To our knowledge only Scarpello et $a l^{27}$ did not find a significant delay of gastric emptying in diabetic patients, even in the seven with dyspeptic symptoms; methodological problems may be at the origin of this discrepancy. In patients with secondary dyspepsia simultaneous assessment of liquid and solid emptying rates were rarely done; Campbell et al's results ${ }^{1}$ indicate, as ours do, that gastroparesis concerns the two components of the meal. Results obtained in the idiopathic dyspepsia patients are more exciting and conflicting: idiopathic dyspepsia is a very common syndrome; it affects patients usually thought to have no objective anomaly and are generally labelled as having functional disorders although without any proof of functional abnormalities. Curiously, such patients were rarely investigated. In a work testing only a liquid meal ${ }^{28}$ no objective delay was found. Bertrand $e t{ }^{29}$ have shown an objective delay of gastric emptying in such patients, using nondigestible radio-opaque pellets incorporated into a standard meal and counted on radiograph series taken at hourly intervals. More recently, Cottrell and colleagues ${ }^{30}$ found a delay of solid gastric emptying in five patients with severe idiopathic dyspepsia, whereas only three out of 14 patients of You et al $^{23}$ have a radiological stasis of a barium meal. In the present study, patients with idiopathic dyspepsia were evaluated and compared with patients with dyspeptic symptoms of known origin (postvagotomy dyspepsia and secondary dyspepsia) and to controls. A delay of gastric emptying was found in the idiopathic dyspepsia group; however, this delay concerns only one out of two of those patients (Table 2); it is significant only for gastric emptying of liquids, and is smaller than that observed in the secondary dyspepsia and postvagotomy dyspepsia group (Fig. 1). Several hypothesis could account for this: (a) a lack of sensitivity in our method for detecting an abnormal gastric emptying seems improbable because under similar conditions high percentages of abnormal results were found in the other patients studied (postvagotomy dyspepsia and secondary dyspepsia groups) although they had similar symptoms, (b) the presence of other gastrointestinal functional 
disorders inducing the symptoms whatever their nature or their origin, (c) finally the symptoms may not correspond to any gastrointestinal disturbance. Another peculiarity of the idiopathic dyspepsia group is the loss of discrimination between gastric emptying of liquids and solids evidenced in 12 out of 27 patients; such a finding has already been described in elderly subjects ${ }^{31}$ and in asymptomatic diabetic patients. 'Its mechanism remains unknown. Although a solid-liquid discrimination is found in the other groups, these results must be accepted with caution because the liquid markers are not entirely specific of the liquid phase but are partially adsorbed on solids. ${ }^{18}$

Cisapride, a new gastrokinetic drug, devoid of the antidopaminergic effects and acting at least in part by release of acetylcholine from terminal neurones but without secretory or parasympaticomimetic side effects ${ }^{32}$ was studied in acute administration. This drug accelerates significantly gastric . emptying of solids in dyspeptic patients considered as a whole. When the seven patients who exhibited gastric emptying delay during the placebo sequence were considered alone, a significant enhancement of both solid and liquid gastric emptying rates was shown. Thus as previously described with metoclopramide ${ }^{33} 34$ it seems that cisapride has a gastrokinetic effect mainly in patients with gastric stasis.

In conclusion this study emphasises the importance of an objective measurement of gastric emptying in dyspeptic patients as (a) the presence of a stasis cannot be predicted by analysis of symptoms particularly in idiopathic dyspepsia patients and (b) the determination of an objective gastric stasis could lead to a better rationale of therapeutic management of these patients, as the action of the gastrokinetic drug cisapride tested in this study seems to concern mainly patients with gastric emptying delay. Trials are now needed to determine if efficacy of cisapride on gastric emptying persists during chronic administration and to correlate its effects on symptoms with those on gastric emptying rates. Such an approach would contribute to a better understanding and therapeutic management of these subjects.

We thank Janssen Le Brun for supplies of cisapride.

\section{References}

1 Campbell IW, Heading RC, Tothill P, Buist TAS, Ewing DJ, Clarke BF. Gastric emptying in diabetic autonomic neuropathy. Gut 1977; 18: 462-7.

2 Heer M, Pirovino M, Japp H, Buhler H, Schmid M. Diabetic gastroparesis and colonic dilatation treated with domperidone. Lancet 1980; 2: 1145-6.

3 Snape WJ, Battle WM, Schwartz SS, Braunstein SN, Goldstein HA, Alavi A. Metoclopramide to treat gastroparesis due to diabetes mellitus. A doubleblind, controlled trial. Ann Intern Med 1982; 96: 444-6.

4 Jian R, Assael T, Ducrot F, Hautefeuille P, Grall Y, Bernier JJ. Effet de la vagotomie fundique sur la vidange gastrique chez l'homme. [Abstract] Gastroenterol Clin Biol 1982; 7: 64.

5 MacGregor IL, Martin P, Meyer JH. Gastric emptying of solid food in normal man and after subtotal gastrectomy and truncal vagotomy with pyloroplasty. Gastroenterology 1977; 72: 206-11.

6 Frank EB, Lange R, McCallum RW. Abnormal gastric emptying in patients with atrophic gastritis with or without pernicious anaemia. [Abstract] Gastroenterology 1981; 80: 1151.

7 Miller LJ, Malagelada JR, Longstreth GF, Go VLW. Dysfunctions of the stomach with gastric ulceration. Dig Dis Sci 1980; 25: 857-64.

8 McCallum RW, Berkowitz DM, Lerner E. Gastric emptying in patients with gastroesophageal reflux. Gastroenterology 1981; 80: 285-91.

9 Hawkins R, Anselmo M, Zamost B et al. Gastric emptying in patients with scleroderma. [Abstract] $J$ Nucl Med 1981; 22: 86.

10 Kassander P. Asymptomatic gastric retention in diabetics (gastroparesis diabeticorum). Ann Intern Med 1958; 48: 797-812.

11 Albibi R, McCallum RW. Metoclopramide: pharmacology and clinical application. Ann Intern Med 1983; 98: 86-95.

12 Brogden RN, Carmine AA, Heel RC, Speight TM, Avery GS. Domperidone. A review of its pharmacological activity, pharmacokinetics and therapeutic efficacy in the symptomatic treatment of chronic dyspepsia and as an antiemetic. Drugs 1982; 24: 360-400.

13 Fox S, Behar J. Pathogenesis of diabetic gastroparesis: a pharmacologic study. Gastroenterology 1980; 78: 757-63.

14 Malagelada JR, Rees WDW, Mazzotta LJ, Go VLW. Gastric motor abnormalities in diabetic and postvagotomy gastroparesis: effect of metoclopramide and bethanechol. Gastroenterology 1980; 78: 286-93.

15 Van de Mierop L, Rutgeerts L, Van den Langenbergh B, Staessen A. Oral domperidone in chronic postprandial dyspepsia. A double-blind placebo controlled evaluation. Digestion 1979; 19: 244-50.

16 Loo FD, Palmer DW, Soergel KH, Kalbfleisch JH, Wood CM. Gastric emptying in patients with diebetes Mellitus. Gastroenterology 1984; 86: 485-94.

17 Van Nueten JM, Schuurkes JAJ. Stimulating effects of cisapride on isolated preparations of stomach, small and large intestine of the guinea pig. [Abstract] Gastroenterolcgy 1984; 86: 1288.

18 Jian R, Vigneron N, Najean Y, Bernier JJ. Gastric emptying and intragastric distribution of lipids in man. 
A new scintigraphic method of study. Dig Dis Sci 1982; 27: 705-11.

19 Bandini P, Malmud L, Rock E, Applegate G, Reilley J. Fisher RS. Gastric emptying of physiologic mixed solid-liquid meal in man. [Abstract] Gastroenterology 1980; 78: 1135.

20 Goldstein HA, Alavi A, Snape WJ. The increase sensitivity of solid scintigraphic gastric emptying. [Abstract] J Nucl Med 1981; 22: 27.

21 Shih WJ, De Land FH, Magoun S, Coupal JJ, Domstad PA. Measurement of gastric emptying time in outlet obstruction. [Abstract] J Nucl Med 1983; 24: 99-100.

22 Rees WDW, Miller LJ, Malagelada JR. Dyspepsia, antral motor dysfunction, and gastric stasis of solids. Gastroenterology 1980; 78: 360-5.

23 You CH, Lee KY, Chey WY, Menguy R. Electrogastrographic study of patients with unexplained, nausea, bloating and vomiting. Gastroenterology 1980; 79: $311-4$

24 Thompson DG, Malagelada JR. Vomiting and the small intestine. Dig Dis Sci 1982; 27: 1121-5.

25 Cowley DJ, Vernon P, Jones T, Glass HI, Cox AG. Gastric emptying of solid meals after truncal vagotomy and pyloroplasty in human subjects. Gut 1972; 13: 176-81.

26 Metzger WH, Cano R, Sturdevant AL. Effect of metoclopramide in chronic gastric retention after gastric surgery. Gastroenterology 1976; 71: 30-2.
27 Scarpello JHB, Barber DC, Hague RV, Cullen DR, Sladen GE. Gastric emptying of solid meals in diabetics. Br Med J 1976; 2: 671-3.

28 Brassinne A, Linsmaux D, Merchie G. Intérêt de la mesure de la vitesse d'évacuation gastrique à la scinticaméra. Acta Gastroenterol Belg 1978; 41: 688-97.

29 Bertrand J, Metman EH, Danquechin Dorval E et al. Étude du temps d'évacuation gastrique de repas normaux au moyen de granules radiopaques. Applications cliniques et validation. Gastroenterol Clin Biol 1980; 4: 770-6.

30 Cottrell CR, Srinsky CA, Martin JL, Mathias JR. Are alterations in gastroduodenal motility responsible for previously unexplained nausea vomiting and abdominal pain. [Abstract] Dig Dis Sci 1982; 27: 650.

31 Moore JG, Tweedy C, Christian PE, Datz FL. Effect of age on gastric emptying of liquid-solid meals in man. Dig Dis Sci 1983; 28: 340-4.

32 Schuurkes JAJ, Verlinden A, Akkermans LMA, Van Nueten JM. Stimulating effects of R. 51619 on antroduodenal motility in the conscious dog. [Abstract] Gastroenterol Clin Biol 1983; 7: 704.

33 Behar J, Ramsby G. Gastric emptying and antral motility in reflux esophagitis: effect of oral metoclopramide. Gastroenterology 1978; 74: 253-6.

34 Hancock BD, Bowen-Jones E, Dixon R, Dymock IW, Cowley DJ. The effect of metoclopramide on gastric emptying of solids meals. Gut 1974; 15: 462-7. 